DOI: $10.17805 /$ zpu.2018.3.7

\title{
Стыд и моральная ответственность организованных коллективов *
}

\author{
A. В. ПРОКОФЬЕВ \\ ИНСТИТУТ ФИЛОСОФИИ РАН; \\ ТУЛЬСКИЙ ГОСУДАРСТВЕННЫЙ ПЕДАГОГИЧЕСКИЙ УНИВЕРСИТЕТ ИМ. Л. Н. ТОЛСТОГО
}

Цель данной статьи - выявить место моральной эмоции стыда в механизмах моральной ответственности организованных коллективов (бизнес-корпораций, самоуправляющихся ассоциаций, государственных организаций). В своих ретроспективных проявлениях моральная ответственность тесно связана с осуждением нарушителя нравственной нормы. Нарушитель подлежит внешнему осуждению, но и от него самого также ожидается осуждение совершенного им поступка. Признаком подлинности самоосуждения принято считать наличие негативных эмоций самооценки, таких как вина и стыд.

В рамках данного исследования используется такое понимание стыда, при котором он является негативной эмоцией, возникающей на фоне действительной или потенциальной осведомленности других людей о совершенном нарушении и сосредоточенной на проявившемся в поступке моральном качестве личности нарушителя. Вина, в свою очередь, не обусловлена внешними факторами и сосредоточена на моральном качестве самого действия и его последствий. Организованные коллективы можно рассматривать в качестве деятелей, способных нести моральную ответственность в силу наличия у них внутрен-

* Статья подготовлена при поддержке РФФИ, проект 16-03-50063 «Роль стыда в моральном опыте: история проблемы и современные подходы к ее разрешению».

The article is prepared within the framework of the project "The Role of Shame in Moral Experience: the History of the Problem and Contemporary Solutions to It" supported by the Russian Foundation for Basic Research (RFBR) (grant No. 16-03-50063). 
них структур принятия решений (термин П. Френча). К примеру, решения бизнес-корпорации можно отграничить от решений ее менеджеров, не выражающих намерений организованного коллектива. Существенным затруднением для признания таких коллективов ответственными моральными деятелями является отсутствие у них аффективной составляющей поведения: тот, кто не способен осуждать себя в эмоциональных формах, не подлежит моральному осуждению. Однако более глубокий анализ свойств организованного коллектива позволяет утверждать, что он обладает функциональными аналогами или субститутами эмоций самооценки. При этом они гораздо больше похожи на индивидуальный стыд, чем на индивидуальную вину. Организованный коллектив способен как выражать стыд, так и опасаться стыда. Эта его особенность должна найти отражение в системе наказания бизнес-корпораций. В их отношении уместно использовать так называемые пристыжающие санкции, наносящие удар по корпоративной репутации.

Ключевые слова: мораль; бизнес-этика; организованные коллективы; моральная ответственность; стыд; корпорация

\section{BВЕАЕНИЕ}

В своих ретроспективных проявлениях моральная ответственность тесно связана с осуждением нарушителя нравственной нормы. Если вменяемый деятель совершает моральное нарушение, т. е. поступок, который негативно воздействует на членов морального сообщества, то он превращается в правомерную мишень для осуждения. Речь идет как о внешнем осуждении, так и о внутреннем. От нарушителя долга ожидается негативная оценка своего поступка, причем знаком подлинности самоосуждения принято считать наличие соответствующих негативных эмоций (болезненных переживаний). Простая констатация того, что деятель причинил морально неприемлемый вред или пренебрег возможностью содействовать благу морально значимого существа, здесь недостаточна. Только факт интенсивного страдания, глубокого недовольства собой подтверждает, что перед нами именно осуждение, а не его имитация.

Основными эмоциональными «проводниками» ретроспективной моральной ответственности считаются хорошо исследованные в психологии морали феномены вины и стыда. Существует давний спор между теоретиками, пытающимися провести разграничительные линии между этими двумя эмоциями. Одна их группа рассматривает в качестве специфического свойства стыда его обязательную связь с присутствием порицающей нарушение или хотя бы просто осведомленной о нем аудитории. Стыд, таким образом, выступает как эмоционально нагруженное самоосуждение, инициированное тем, что деятель осознает, что его образ, возникший в сознании других людей, является неблагоприятным (или хотя бы радикально не соответствующим тому, который он предпочел бы иметь). Значимая для стыдящегося человека аудитория вполне может быть и воображаемой. В этом случае стыд порожден предвосхищением ее реакции на совершенное нарушение. Переживание вины является независимым от внешних факторов, т. е. автономным. Его интенсивность может варьироваться в зависимости от присутствия или отсутствия аудитории. Однако возникновение этой эмоции вполне возможно и без угрозы того, что нарушение будет предано публичности, и даже без размышления нарушителя о такой перспективе (см., например: Бенедикт, 2004; Scheff, 2003).

Аругая группа теоретиков определяет стыд через особый фокус, который имеет негативная самооценка. В случае стыда она касается непосредственно личности нарушителя, а не его поступков, хотя поводом для стыда (во всяком случае, морально значимого стыда) выступают именно предосудительные действия. Стыд является эмо- 
цией, которая фиксирует внимание переживающего ее человека на несоответствии между его реальным и идеальным $Я$ в свете определенного ценностно-нормативного стандарта. Вина же концентрирует внимание деятеля на характере поступка и моральном значении его последствий. Аля многих сторонников этого критерия он заменяет собой критерий автономности/гетерономности. Стыд, с их точки зрения, в той же мере автономен, как и вина (см., например: Tangney, Dearing, 2002; Deonna, Rodogno, Teroni, 2012).

Я полагаю, что существуют серьезные обстоятельства, подталкивающие к тому, чтобы соединить некоторые элементы этих позиций и рассматривать стыд в качестве эмоции, которая совмещает акцент на негативной оценке личности с необходимостью Аля своего возникновения хотя бы воображаемой аудитории (Прокофьев, 2017). Именно с таким пониманием стыда я хотел бы обратиться к проблеме моральной ответственности за коллективную деятельность. При этом в моем поле зрения будет находиться только один из двух аспектов коллективной моральной ответственности ответственность организованных коллективов. Аругой ее аспект (ответственность индивидов за деятельность своих групп) требует отдельного анализа.

\section{ОРГАНИЗОВАННЫЙ КОААЕКТИВ - \\ ОСОБЫЙ ТИП МОРААЬНЫХ АЕЯТЕАЕЙ}

Моральная ответственность организованных коллективов (бизнес-корпораций, самоуправляющихся ассоциаций, государственных организаций) возможна лишь в том случае, если признать их теми самыми деятелями, которые осуществляют выбор, изменяющий положение членов морального сообщества. Основания для признания их таковыми могут быть связаны как с благотворным әффектом наделения организованных коллективов статусом вменяемого деятеля, так и с выявлением достаточной степени подобия между индивидуально ответственным индивидом и некоторыми типами коллективов. Первая причина, взятая изолированно от второй, вызывает определенные нарекания. Наделение коллектива свойствами деятеля оказывается в этом случае чистой условностью. Все те, кто рассматривает его в этом качестве, попадают в ситуацию плохо прикрытого самообмана: они знают об условности наделения коллективов статусом ответственного деятеля и вместе с тем готовы искренне вменять ему в вину те или иные моральные нарушения.

Гораздо более обоснованной является одновременная апелляция к двум основаниям. Благотворные результаты наделения организованных коллективов статусом ответственных деятелей выступают как мощный дополнительный мотив для выявления подобия между индивидуальной и коллективной деятельностью, несмотря на плотный слой поверхностных различий между ними. Именно эту линию рассуждения начиная с середины 1970-х годов попытался подробно разработать американский социальный философ П. Френч (см.: French, 1984, 1992, 1995, 2011).

Френч попытался показать, что бизнес-корпорации (и другие схожие с ними организованные коллективы) обладают намерениями, которые невозможно свести к намерениям их индивидуальных руководителей. И это позволяет всерьез обсуждать их моральную ответственность. Хотя с течением времени Френч стал придавать большее значение первому из двух оснований наделения организованных коллективов статусом морального деятеля (их способности причинять незаслуженный, морально неприемлемый ущерб), «функциональная способность к намеренной деятельности» (French, 2011: 214) все равно остается для него необходимым условием для признания 
любого деятеля морально ответственным. Эта способность обеспечивается за счет наличия у организованных коллективов специальных структур, которые разрабатывают планы, принимают решения и проводят эти решения в жизнь (Френч называет их «внутрикорпоративными структурами принятия решений»- англоязычная аббревиатура CIDS).

CIDS определяют ролевые позиции и уровни соподчинения работников организации, а также порядок признания планов и решений планами и решениями корпоративного целого. В силу существования CIDS планы и решения организации приобретают существенную степень независимости от намеренных действий их индивидуальных разработчиков. Постоянная смена управленческого персонала не разрушает единство и согласованность коллективной деятельности. «Приведенные в движение CIDS, замечает Френч, - субординируют и синтезируют намерения, желания, действия различных человеческих личностей (а иногда и поведение машин) в действие организации» (French, 2011: 277).

Именно анализ активности CIDS позволяет внешнему наблюдателю идентифицировать специфический тип намерений, а как следствие, морально оценивать основанную на них деятельность. Это обстоятельство не устраняет моральную ответственность отдельных индивидов, участвующих в работе CIDS, но если поступки этих индивидов прямо соответствуют процедурам организации или используют остающиеся в них бреши, то они соединятся в нарушение уже иного, коллективного субъекта ответственности. Естественно, что в формировании этого субъекта и его нарушений задействованы не только формальные правила, но и традиционные практики организованного коллектива (они дополняют официальные процедуры, а иногда даже противоречат им). Свой вклад в морально предосудительную деятельность, которая является в подлинном смысле коллективной, вносит также терпимая реакция руководства и рядовых членов организации на нарушения официальных процедур (там же: 219).

Как и в случае с индивидуальной деятельностью и моральной ответственностью за нее, коллектив признается моральным субъектом не только в связи с признанием того, что его планы и решения могли бы быть Аругими, если бы он принял во внимание моральные нормы, но и в связи с признанием его способности к изменению своих намерений и действий в будущем. Одна из основных функций CIDS состоит в том, чтобы корректировать деятельность организации на основе прошлых ошибок и неудач. Коллективный деятель является самообучающимся. Это касается не только сугубо деловых просчетов, но и моральных нарушений, которые, будучи отрефлексированными персоналом организации, могут привести к изменению ее культуры и нормативной основы функционирования (там же: 219).

\section{АФФЕКТИВНАЯ СТОРОНА АЕЯТЕАЬНОСТИ \\ ОРГАНИЗОВАННЫХ КОААЕКТИВОВ}

Пытаясь обосновать морально ответственный характер организованных коллективов, Френч длительное время прибегал к понятию «корпоративная личность» и оказывался близок к пониманию намеренной деятельности корпораций через коллективные убеждения и желания (French, 1984: 41-47). Однако позднее, опасаясь, что такая трактовка намеренности превратит коллективные намерения в простую метафору, он перешел к сугубо функционалистской трактовке намерения и к использованию вместо понятия «корпоративная личность» понятия «корпоративный деятель». Намерен- 
ность, обеспечиваемая CIDS, тождественна для него способности к формированию планов на будущее (French, 1995: 10-12; Bratman, 1987). Однако такое снижение требований к намеренной деятельности оказалось чревато другой проблемой. На этом фоне уже применение понятия «моральная ответственность» к коллективным субъектам может оказаться сугубо метафорическим. Как было подчеркнуто во вводном пункте нашей статьи, моральная ответственность тесно связана со способностью тех, на кого она возлагается, осуждать самих себя в форме болезненных переживаний. Этот элемент оказывается отсутствующим в практике тех деятелей, которые лишены всего набора свойств человеческой личности.

В современной теории моральной ответственности этот аргумент часто артикулируют в категориях, использованных в работе П. Стросона «Свобода и негодование» (Strawson, 2008: 1-28). Морально ответственным деятелем является тот, кто, становясь нарушителем, вызывает у окружающих негодование. Цель негодующей реакции состоит в том, чтобы вызвать у нарушителя реактивное эмоционально нагруженное самоосуждение. Но если нарушитель не способен к формированию «реактивных установок》 по отношению к действиям других и в особенности к своим собственным действиям, то негодование бессмысленно, а причисление нарушителя к группе ответственных деятелей невозможно. Аля некоторых исследователей отсутствие у корпораций субстрата для переживания эмоций закрывает вопрос об их морально ответственном статусе (с разной степенью жесткости эта мысль выражена Р. Ае АжорАжем (De George, 1986: 62), М. Хэни (Haney, 2004: 401), Э. Сэпинуолл (Sepinwall, 2017: 157-159). Аругие теоретики находят в коллективной практике аналоги аффективной составляющей моральной деятельности.

Так, А. Толлефсен предлагает рассматривать в этом качестве заместительные переживания отдельных членов организации. Они могут переживать негативные эмоции самооценки именно в этом своем ролевом качестве и совершать в этой связи действия, которые они не совершили бы как независимые от организации индивиды. Именно так формируется аффективная сторона реакции организованного коллектива на собственные нарушения (см.: Tollefsen, 2008: 11; 2015: 130-133). Аругой вариант движения в том же направлении - использование того понимания коллективного субъекта, которое разработала М. Гильберт: коллективный субъект складывается, по ее мнению, на основе совместной решимости его членов действовать определенным образом. Связанные с этой решимостью эмоции отдельных членов коллектива, в том числе эмоции самооценки, являются коллективными эмоциями (Gilbert, 2002).

Однако в обоих этих случаях возникает серьезный разрыв между эмоциями, которые выражают принятие на себя ответственности, и тем, что превращает коллектив в морального деятеля, - его организованным характером. Коллектив совершает определенные действия как единое целое, приобретающее относительную независимость от своих членов, а переживает негативные эмоции самооценки исключительно через сознание входящих в него людей. В случае принятия и реализации коллективного решения индивиды определяются в своих действиях нормами коллективной жизни, а в случае коллективных эмоций, напротив, коллектив зависит от способности его отдельных членов чувствовать сожаления, вину или стыд за поведение коллективного целого. И, что особенно важно, эта их способность находится вне досягаемости для коллективных решений и норм. Такой разрыв препятствует признанию того, что реактивные эмоции отдельных людей являются слагаемыми эмоциональной реакции самого коллектива. 
Френч, принявший стросонианский вызов, попытался в этой связи обнаружить полноценный функциональный субститут реактивных переживаний, не зависящий от такого случайного фактора, как способность отдельных членов организации чувствовать что-то в ее отношении. Он полагает, что выражение сожалений представителем корпоративного персонала, исполняющим свои должностные обязанности, является вполне адекватной формой проявления коллективных эмоций, несмотря на то что он или она не чувствуют никаких сожалений. Об этом можно вести речь, поскольку именно таково корректное описание происходящего на индивидуальном уровне в терминах организованного коллективного опыта. Аффективный компонент этого опыта конвенционален, перформативен и ритуалистичен. Искренняя озабоченность организованного коллектива своим соответствием определенным ценностям выражается в соблюдении этого ритуала и существовании внутренней коммуникации по поводу средств сохранения этого соответствия (см: French, 2011: 278-279; подробнее: French, 2012: Электронный ресурс).

Г. Бьорнссон и К. Хесс предприняли попытку расширить рамки функционального подхода к коллективным реактивным переживаниям. По их мнению, функциональные субституты моральных эмоций самооценки обладают полноценным аналогом болезненности последних. Организация, занимающаяся преодолением факторов, которые стали причиной пренебрежения моральными нормами, проходит через «разрушительный внутренний конфликт». Изменение устойчивых практик, изменение системы ролей и персонального состава менеджеров, череда индивидуальных взысканий - все это явления, которых любая организация стремится избежать, но вынуждена претерпевать в случае нарушения моральной нормы (Bjornsson, Hess, 2017: 288). Что касается озабоченности организации своим моральным «послужным списком», то она, по мнению Бьорнссона и Хесс, проявляется не только в извинениях и компенсациях, но также в 1) изменении корпоративных норм, требующих от персонала большей внимательности к морально значимым вопросам, 2) проведении внутреннего этического аудита, 3) найме дополнительных специалистов (например, экспертов в области оценки экологического ущерба или вредящих воздействий корпоративной практики на общественную среду) и наделении их контрольными полномочиями (там же: 289-291).

\section{СТЫА КАК ФОРМА ПРОЯВАЕНИЯ МОРААЬНОЙ ОТВЕТСТВЕННОСТИ ОРГАНИЗОВАННЫХ КОААЕКТИВОВ}

Какие же индивидуальные переживания дублируют квазиэмоции организации? Внутри возникшего совсем недавно спора об аффективной составляющей моральной ответственности организованных коллективов этот вопрос оказался слабо отрефлексированным. У Бьорнссона и Хесс коллективы испытывают подобие вины; другие эмоции самооценки не упоминаются ими вовсе. Толлефсен также ведет речь о вине, но допускает возможность развернуть свое рассуждение в сторону коллективного стыда. Френч обсуждает нерасчлененный ряд, состоящий из раскаяния, сожаления, вины и стыда. Однако дифференцированный подход в этой сфере необходим, и основа для него заложена в более ранних исследованиях коллективной моральной ответственности (в особенности в ранних работах Френча, провозгласившего когда-то, что мораль корпораций - это «мораль стыда» (French, 1992: 173)).

Если мы возьмем за точку отсчета первую особенность стыда - его связь с внешней оценкой, со стремлением сохранить благоприятный имидж в глазах других лю- 
дей, то, на мой взгляд, реактивные установки организованных коллективов будут близки именно к стыду. Этой мысли противоречит утверждение Бьорнссона и Хесс о возможности «прямого признания ответственности» бизнес-корпораций ( «прямого», т. е. независимого от «стратегических соображений», среди которых - стремление не потерять благоприятный корпоративный имидж, а с ним и перспективу коммерческого успеха) (Bjornsson, Hess, 2017: 290). Однако мне представляется, что это лишь сугубо теоретическая возможность. Имиджевые соображения и моральная самооценка не просто связаны, а тесно переплетены между собой в деятельности организаций. Не случайно парадигмальный случай моральной ответственности корпорации, используемый самими Бьорнссоном и Хэсс, касается реакции воображаемой фирмы на факт загрязнения ею окружающей среды, вскрытый неким общественным движением (там же: 289). Сугубо самостоятельное и при этом не связанное с угрозой публичной огласки обнаружение нарушений в корпоративной среде является редкостью. В этом отношении организованный коллектив не похож на полностью автономный моральный субъект. Но он не является и подобием расчетливого психопата, Аля которого не существует иных критериев, кроме итоговой выгоды. Просто для сохранения озабоченности моральной стороной собственной деятельности ему необходима общественная среда, готовая выносить суждения о моральном качестве его практики. В этом смысле ответственный организованный коллектив больше похож на человека, у которого чувство стыда развито гораздо сильнее, чем чувство вины.

Вторая особенность стыда состоит в том, что негативные переживания связаны непосредственно с качеством личности, с ее несоответствием определенным ценностям, которое отразилось в том или ином поступке. Само по себе действие, т. е. совершенное деятелем нарушение, при этом не является смысловым центром переживаний. Отсюда вытекает тот факт, что стыдящийся человек придает менышее значение извинениям перед пострадавшими от его действий людьми и возмещению их потерь, поскольку извинения и компенсация сами по себе не меняют его личных характеристик. Последнее обстоятельство как будто бы противоречит тезису о том, что моральная ответственность организованных коллективов выражается в структурных подобиях чувства стыда. Все ее исследователи указывают на извинения, сопровождающиеся компенсацией потерь пострадавших, как на важнейшее проявление реактивных установок коллектива. Однако не следует забывать, что свидетельством искренности извинений и моральной значимости компенсации они все равно считают усилия менеджмента, ведущие к изменению идентичности организации. Такие усилия требуют рефлексии, больше напоминающей стыд, чем вину.

Примечательно, что в отличие от индивидуального контекста самоосуждение, направленное на «личность», не грозит организации болезненным тупиком, который описывают некоторые исследователи стыда. Индивид, обладающий, словами Френча, «непрозрачной машинерией поступка», как правило, не знает, какие действия надо предпринять для изменения собственной личности, хотя хорошо представляет себе, что надо сделать в порядке извинения и компенсации пострадавшим (French, 2011: 217). В этих условиях осознание моральной ущербности собственной личности легко превращается в деструктивный фактор (ведет к депрессии и самоизоляции). Вина менее разрушительна, чем стыд. Организованный коллектив находится в иной ситуации. Френч убедительно демонстрирует, что у корпораций «машинерия действия» является «прозрачной», поскольку она отражается в «линиях и квадратах» схемы управленческого процесса (там же). Ее изменение проще представить себе как более или менее 
очевидный план последовательных мероприятий. Поэтому в случае организованного коллектива мы имеем не просто подобие стыда, но и основания полагать, что это подобие может играть роль әффективного средства самопреобразования.

\section{КОААЕКТИВНАЯ АЕЯТЕАЬНОСТЬ, СТЫА И ПРАВОВЫЕ САНКЦИИ}

Специфика моральной ответственности организованных коллективов отражается на характере применяемых к ним правовых санкций (или, во всяком случае, должна отражаться на них). Аля того чтобы проследить эту связь, необходимо иметь в виду основные условия моральной оправданности правовых санкций. Во-первых, правовые санкции должны отвечать ретрибутивным моральным интуициям, т. е. а) быть реальным, а не условным воздаянием (нарушитель должен нести чувствительные потери и подвергаться чувствительным для него ограничениям), б) обеспечивать соразмерность воздаяния общественно опасным последствиям действий нарушителя и тому, насколько эти последствия зависели от его намерений. Во-вторых, правовые санкции должны обеспечивать предотвращение будущих нарушений как в отношении конкретного нарушителя, который им подвергается, так и в отношении потенциальных нарушителей, осведомленных о возможности подвергнуться санкциям. В-третьих, санкции должны ставить деятеля в такую ситуацию, которая в наибольшей степени способствует возникновению болезненного самоосуждения (она выступает в качестве коммуникативного послания нарушителю, которое в идеале должно вести к осознанию им своей виновности). В-четвертых, санкция должна отчетливо свидетельствовать о предосудительном характере действия, запрещенного законом (обладать моральной экспрессивностью).

Наказание организованных коллективов в свете этих условий оказывается крайне сложной проблемой. Сосредоточимся на том ее аспекте, который связан с правовыми санкциями в отношении бизнес-корпораций. В современной бизнес-этике очень популярна лапидарная фраза английского лорда-канцлера, барона Терлоу о том, что у «корпорации нет души, которая может быть проклята, и нет тела, чтобы дать ей пинка». Это высказывание отражает два важных затруднения корпоративного наказания. Первое связано с отсутствием «тела», т. е. с отсутствием возможности адресного сурового обращения, необходимого для реализации всех четырех условий морально обоснованного наказания. Роль такого обращения не может играть наказание индивидуальных менеджеров, поскольку эта санкция а) имеет неправильный в ретрибутивном отношении объект (коллектив как целое ускользает от неблагоприятного воздействия), б) она недостаточно эффективна как средство предотвращения будущих корпоративных нарушений, поскольку не влияет на целый ряд истоков таких нарушений (тех, которые коренятся в специфике корпоративных CIDS). Аругими словами, нужны санкции, которые затрагивают корпорацию в целом. Таковы денежные штрафы и упразднение юридического лица. Однако штрафы, как правило, перекладываются на плечи клиентов фирмы и не несут достаточной коммуникативной и экспрессивной нагрузки, а упразднение юридического лица дает возможность корпорации восстановить свои структуры под другим названием. Второе затруднение связно с отсутствием «души», испытывающий страх проклятия. Трудно представить себе реализацию коммуникативной функции наказания, если оно имеет дело с субъектом, который в принципе не может быть озабочен непрагматическими последствиями своего нарушения. 
Наличие функциональных аналогов эмоционально нагруженного самоосуждения, которые были проанализированы выше, дает надежду на преодоление затруднений, зафиксированных в афоризме барона Терлоу. А то, что они структурированы по образцу переживания стыда, задает конкретные формы воплощения этой надежды. Корпоративное «тело» оказывается уязвимо для карательных «пинков» государственной власти в области своей репутации, от которой напрямую зависит ее предпринимательский успех. Подрыв репутации без возможности провести спасительный ребрендинг служит той формой сурового обращения, которая направлена на коллективное целое и не может быть переложена на чужие плечи. Если функциональные аналоги эмоционально нагруженного самоосуждения так и не возникают, то подобное обращение создает нарушителю достаточно серьезные затруднения, обладающие ретрибутивным и предупредительным значением. Если же не откликнувшийся на послание государства корпоративный деятель продолжает допускать серьезные нарушения, то в качестве наказания могут выступать уже не удары по репутации, а прямое вмешательство в систему управления корпорацией: принудительное изменение нормативной базы, назначение наблюдателей в совет директоров и т. А. и т. п. Таков еще один, даже более суровый способ воздействия на корпоративное «тело». Однако есть основания полагать, что в значительном количестве случаев отклик корпоративного деятеля все же будет иметь место, между карающим государством и корпорацией завяжется коммуникация, которая ведет к более или менее успешному преобразованию пристыженного коллективного деятеля на основе его собственных усилий.

В своих ранних работах Френч попытался создать модель системы правовых санкций против корпораций, которая учитывала бы, что корпоративная моральная ответственность должна пониматься в перспективе способности нарушителя испытывать стыд, а не вину. Ключевым инструментом наказания корпораций он посчитал организованное по приговору суда широкое негативное паблисити. Эффективность негативного паблисити в отношении корпоративного преступления, по Френчу, должны обеспечивать следующие факторы: а) антирекламный продукт и способы его распространения будут иметь желаемое воздействие на публику, поскольку исполнением приговора будут заниматься профессионалы в сфере PR, чьи услуги будет вынуждена оплачивать сама корпорация, б) предпринимаемые меры пристыжения не сольются с общим антикорпоративным шумом в массмедиа, поскольку в отличие от этого шума будут опираться на вызывающее уважение решение суда, удостоверяющее факт нарушения (French, 1985).

Аля того чтобы не использовать это довольно мощное карающее средство без достаточных оснований, Френч предложил двухчастную процедуру применения корпоративных наказаний. Он исходил из того, что, несмотря на большую прозрачность «машинерии действия» коллективных субъектов, у внешнего наблюдателя часто остаются сомнения в том, является ли нарушение подлинно корпоративным. Поэтому санкции против корпорации, в последовательности от негативного паблисити к прямому вмешательству в управление, должны применяться только после предоставления корпорации возможности изменить свои CIDS, т. е. после того, как она представит суду план самопреобразовании и попытается его реализовать. Аишь вторичное нарушение должно свидетельствовать для суда, что перед ним результат намеренной коллективной деятельности. Таким образом, можно сказать, что Френч предложил создать институционализированное подобие индивидуальной боязни стыда (см.: French, 1991: 211-220; 2011: 286-300)1. 


\section{ЗАКАЮЧЕНИЕ}

У предложенной Френчем системы наказания корпораций много критиков. Некоторые из них отталкиваются от общей принципиальной недопустимости пристыжающих или позорящих наказаний. Мне эта аргументация не кажется хоть сколько-то убедительной, поскольку она не может в случае корпораций опираться на апелляцию к унижению достоинства личности ${ }^{2}$. Аругие критики указывают на слабости концепции Френча, связанные с недостаточной силой воздействия негативного паблисити. Однако эти слабости либо предвосхищены самим Френчем, либо могут быть сняты за счет получения структурами, обеспечивающими исполнение наказаний, некоторых дополнительных полномочий (например, полномочий по ограничению корпоративных PR-кампаний по восстановлению имиджа). Более пристального внимания заслуживают возражения А. Корлетта, отталкивающиеся от идеи пропорциональности наказания. Корлетт предположил, что пристыжающие наказания дают менеджменту корпораций возможность а) уклониться от ответственности за принесшие вред решения, б) сэкономить на компенсации потерь пострадавшим или их родственникам. Поэтому в случаях, похожих на катастрофическую аварию 1984 г. на химическом заводе американской компании «Юнион Карбайд» в г. Бхопал (Индия), наказание корпорации через негативное паблисити выглядит как попрание чувства справедливости (Corlett, 2013: 217-220).

Эти возражения могли бы иметь характер окончательного приговора концепции Френча, если бы не опирались на ее недопонимание. Френч ищет возможность наказания корпорации как целого не в ущерб, а параллельно ответственности принимающих решения индивидов. Организация негативного паблисити корпорации не заменяет наказания менеджеров, а дополняет его. Точно так же она не замещает собой компенсации ущерба (которую трудно вообще считать наказанием). Наконец, пристыжающие наказания изначально являются для Френча не единственной и не самой жесткой мерой, дотягивающейся до корпоративного «тела». Наряду с ними присутствуют разные формы прямого вмешательства в корпоративное управление.

\section{ПРИМЕЧАНИЯ}

${ }^{1}$ Ажэкет указывает на то, что современный теоретический дискурс в отношении оправданности пристыжающих наказаний формируется в отрыве от реалий в сфере распространения информации (прежде всего без учета роли сети Интернет) (Ажекет, 2016: 147). Это очень верное замечание. Модель корпоративных наказаний Френча также требует дополнительного обсуждения применительно к этим условиям. Однако в рамках данной короткой статьи сделать это не представляется возможным.

2 Возражения этого типа, казалось бы, поддерживает название корпоративных пристыжающих наказаний, которое использовал Френч, - «наказания Эстер Прин» (Эстер Прин - героиня известного романа Натаниэля Готорна «Алая буква», которая подверглась клеймению за супружескую неверность). Однако это провокационное название призвано подчеркнуть как сходство этих наказаний с практикой клеймения или приковывания к позорному столбу, так и отличие, которое состоит в том, что в корпоративном контексте публичное пристыжение теряет характеристики, связанные с унижением достоинства.

\section{СПИСОК АИТЕРАТУРЫ}

Бенедикт, Р. (2004) Хризантема и меч: Модели японской культуры. М. : РОССПЭН. 256 с. Ажекет, Аж. (2016) Зачем нам стыд? Человек vs. общество. М. : Альпина нон-фикшн. 244 с. Прокофьев, А. В. (2017) Социализированная и десоциализированная концепции стыда: их специфика и возможности соединения // Философия и общество. № 2 (83). С. 68-86. 
Bjornsson, G., Hess, K. (2017) Corporate Crocodile Tears? On the Reactive Attitudes of Corporate Agents // Philosophy and Phenomenological Research. Vol. XCIV. № 2. P. 273-298.

Bratman, M. (1987) Intention, Plans, and Practical Reason. Cambridge : Harvard University Press. 200 p.

Corlett, A. J. (2013) Responsibility and Punishment. Dordrecht : Springer. 266 p.

De George, R. (1986) Corporations and Morality // Shame, Responsibility, and the Corporation / Ed. by H. Curtler. N. Y. : Haven Publications. P. 59-75.

Deonna, J. A., Rodogno, R, Teroni, F. (2012) In Defense of Shame: the Faces of an Emotion. N. Y. : Oxford University Press. 288 p.

French, P. A. (1984) Collective and Corporate Responsibility. N. Y. : Columbia University Press. 215 p.

French, P. A. (1985) The Hester Prynne Sanction // Business \& Professional Ethics Journal. Vol. 4. № 2. P. 19-38.

French, P. A. (1991) Corporate Crimes and Innovative Punishments // Coordination of Social Values / Ed. by K. Koford and J. Miller. Ann Arbor : University of Michigan Press. P. 203-220.

French, P. A. (1992) Responsibility Matters. Lawrence : University Press of Kansas. 229 p.

French, P. A. (1995) Corporate Ethics. Fort Wotrh : Harcourt Brace College Publishers. 380 p.

French, P. A. (2011) War and Moral Dissonance. Cambridge : Cambridge University Press. 343 p.

French, P. A. (2012) Corporate Affectivity and Membership in the Moral Community (presentation at Oxford University) [Электронный ресурс] // Slideplayer.com. URL: http://slideplayer.com/slide/1412408 (дата обращения: 10.01.2018).

Gilbert, M. (2002) Collective Guilt and Collective Guilt Feelings // Journal of Ethics. Vol. 6. № 2. P. 115-143.

Haney, M. (2004) Corporate Loss of Innocence for the Sake of Accountability // The Journal of Social Philosophy. Vol. 35. № 3. P. 391-412.

Sepinwall, A. J. (2017) Blame, Emotion, and the Corporation // The Moral Responsibility of Firms / Ed. by E. W. Orts and N. Craig Smith. Oxford: Oxford University Press. P. 143-168.

Scheff, T. J. (2003) Shame in Self and Society // Symbolic Interaction. Vol. 26. № 2. P. 239-262.

Strawson, P. F. (2008) Freedom and Resentment and Other Essays. N. Y. : Routledge. 288 p.

Tangney, J. P., Dearing, R. L. (2002) Shame and Guilt. N. Y. : Guilford Press. 272 p.

Tollefsen, D. P. (2008) Affectivity, Moral Agency, and Corporate-Human Relations // APA Newsletters. Newsletter on Philosophy and Law. Vol. 7. № 2. P. 9-13.

Tollefsen, D. P. (2015) Groups as Agents. Malden : Polity. 153 p.

Аата поступления: 16.01 .2018 2.

SHAME AND MORAL RESPONSIBILITY OF ORGANISED COLLECTIVES

\section{A. V. PROKOFYEV \\ RAS INSTITUTE OF PHILOSOPHY; \\ tula State LeV Tolstoy Pedagogical University}

The goal of this paper is to determine the role played by the moral emotion of shame in the mechanisms of the moral responsibility of organised collectives (corporations, self-regulated associations, governmental organisations). Retrospective moral responsibility is closely connected with the blame attributed to a transgressor of a moral norm. They are liable for external blame, and they are expected to blame themselves. Self-blame is considered to be genuine only when a negative self-evaluation is accompanied with painful negative emotions of self-appraisal, such as guilt and shame.

Within the research, the author perceives shame as a negative emotion appearing in the background of other people's actual or potential awareness of the transgression and concentrated on the transgressor's moral quality revealing itself in their deed. Guilt, in its turn, is not stipulated by external factors and concentrated on the moral quality of the action and its consequences. Organised col- 
lectives may be regarded as agents that can bear moral responsibility. This status is ensured by their internal decision structures (the term of P. French). For example, decisions of corporations can be distinguished from the decisions of their managers that do not express a collective intention. One of the main obstacles to the admission of organised collectives into the community of moral agents is their alleged lack of affective reactions: an agent who is incapable of emotional self-blame is not subject to moral blame. However, a deeper analysis of the features of organised collectives makes it possible to state that they are endowed with some functional analogues or substitutes of emotional self-appraisal. Those are more similar to individual shame than individual guilt. An organised collective can both express and fear shame. This peculiarity of organised collectives should be reflected in the system of corporate punishment. It is appropriate to use so-called shaming legal sanctions against transgressing corporations, which causes serious damage to their reputation.

Keywords: morality; business ethics; organised collectives; moral responsibility; shame; corporation

\section{REFERENCES}

Benedict, R. (2004) Kbrizantema i mech: Modeli iaponskoi kul'tury. Moscow, ROSSPEN publ. 256 p. (In Russ.)

Jacquet, G. (2016) Zachem nam styd? Chelovek vs. obshchestvo. Moscow, Al'pina non-fikshn publ. 244 p. (In Russ.)

Prokofyev, A. V. (2017) Sotsializirovannaia i desotsializirovannaia kontseptsii styda: ikh spetsifika i vozmozhnosti soedineniia. Filosofiia $i$ obshchestvo, no. 2 (83), pp. 68-86. (In Russ.)

Bjornsson, G. and Hess, K. (2017) Corporate Crocodile Tears? On the Reactive Attitudes of Corporate Agents. Philosophy and Phenomenological Research, vol. XCIV, no. 2, pp. 273-298.

Bratman, M. (1987) Intention, Plans, and Practical Reason. Cambridge, Harvard University Press. 200 p.

Corlett, A. J. (2013) Responsibility and Punishment. Dordrecht, Springer. 266 p.

De George, R. (1986) Corporations and Morality. Shame, Responsibility, and the Corporation, ed. by H.Curtler. New York, Haven Publications. Pp. 59-75.

Deonna, J. A., Rodogno, R. and Teroni, F. (2012) In Defense of Shame: the Faces of an Emotion. New York, Oxford University Press. 288 p.

French, P. A. (1984) Collective and Corporate Responsibility. New York, Columbia University Press. 215 p.

French, P. A. (1985) The Hester Prynne Sanction. Business \& Professional Ethics Journal, vol. 4, no. 2, pp. 19-38.

French, P. A. (1991) Corporate Crimes and Innovative Punishments. In: Coordination of Social Values, ed. by K. Koford and J. Miller. Ann Arbor, University of Michigan Press, pp. 203-220.

French, P. A. (1992) Responsibility Matters. Lawrence, University Press of Kansas. 229 p.

French, P.A. (1995) Corporate Ethics. Fort Wotrh, Harcourt Brace College Publishers. 380 p.

French, P. A. (2011) War and Moral Dissonance. Cambridge, Cambridge University Press. 343 p.

French, P. A. (2012) Corporate Affectivity and Membership in the Moral Community (presentation at Oxford University). Slideplayer.com [on-line] Available at: http://slideplayer.com/slide/ 1412408 (accessed 10.01.2018).

Gilbert, M. (2002) Collective Guilt and Collective Guilt Feelings. Journal of Ethics, vol. 6, no 2, pp. 115-143.

Haney, M. (2004) Corporate Loss of Innocence for the Sake of Accountability. The Journal of Social Philosophy, vol. 35, no 3, pp. 391-412.

Sepinwall, A. J. (2017) Blame, Emotion, and the Corporation. The Moral Responsibility of Firms, ed. by E. W. Orts and N. Craig Smith. Oxford, Oxford University Press, pp. 143-168.

Scheff, T. J. (2003) Shame in Self and Society. Symbolic Interaction, vol. 26, no. 2, pp. 239-262.

Strawson, P. F. (2008) Freedom and Resentment and Other Essays. New York, Routledge. 288 p.

Tangney, J. P. and Dearing R.L. (2002) Shame and Guilt. New York, Guilford Press. 272 p. 
Tollefsen, D. P. (2008) Affectivity, Moral Agency, and Corporate-Human Relations. APA Newsletters. Newsletter on Philosopby and Law, vol. 7, no. 2, pp. 9-13.

Tollefsen, D. P. (2015) Groups as Agents. Malden, Polity. 153 p.

Submission date: 16.01 .2018$.

Прокофьев Андрей Вячеславович - доктор философских наук, ведущий научный сотрудник сектора этики Института философии РАН; профессор кафедры философии и культурологии Тульского государственного университета имени $\Lambda$. Н. Толстого. Адрес: 109240 , Россия, г. Москва, ул. Гончарная 12, стр. 1. Тел.: +7 (495) 697-93-68. Эл. адрес: avprok2006@mail.ru

Prokofyev Andrey Vyacheslavovich, Doctor of Philosophy, Leading Research Fellow, Sector of Ethics, RAS Institute of Philosophy; Professor, Department of Philosophy and Culture Studies, Tula State Lev Tolstoy Pedagogical University. Postal address: 12, Bldg. 1, Goncharnaya St., Moscow, Russian Federation, 109240. Tel.: +7 (495)697-93-68. E-mail: avprok2006@mail.ru 